\title{
Canadian primary care doctors face shortage of protective equipment
}

\author{
n Cite as: CMAJ 2020 April 6;192:E380-1. doi: 10.1503/cmaj.1095856
}

Posted on cmajnews.com on March 20, 2020

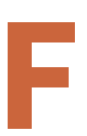
amily doctors worried about potential exposure to coronavirus disease 2019 (COVID-19) are using social media to swap patterns for face masks and reusable gowns, while decrying a shortage of personal protective equipment.

"I got an update from Public Health saying that if I do a home visit, I'm expected to put a mask on myself, and wear an isolation gown and a face shield," says Dr. Carola Collins, a palliative care physician and family doctor in Ingersoll, Ont.

But Collins has no isolation gowns, no face shields and, until earlier this week when she began making her own out of quilting scraps, she was down to her last three surgical masks. She can't find any equipment and is concerned about transferring the virus during her work in the community, especially when visiting palliative patients at homes.

Other community doctors in a 7000-member Facebook group are posting about equipment shortages and sharing sources for reusable gowns and do-it-yourself face shields. And Collins' nursing colleagues in Ontario, especially those who conduct home visits, have complained of similar equipment shortages.

"The government has given us nothing," said Dr. Javed Alloo, a family doctor in North Toronto. "We had a couple of gowns left over from H1N1 in our clinic. Hopefully we can get away with surgical masks... I have been talking to many doctors who don't have anything."

During the severe acute respiratory syndrome (SARS) crisis of 2003, health care practitioners received kits of personal protective equipment to ensure they could treat patients, according to Dr. Yoni Freedhoff, an associate professor of family

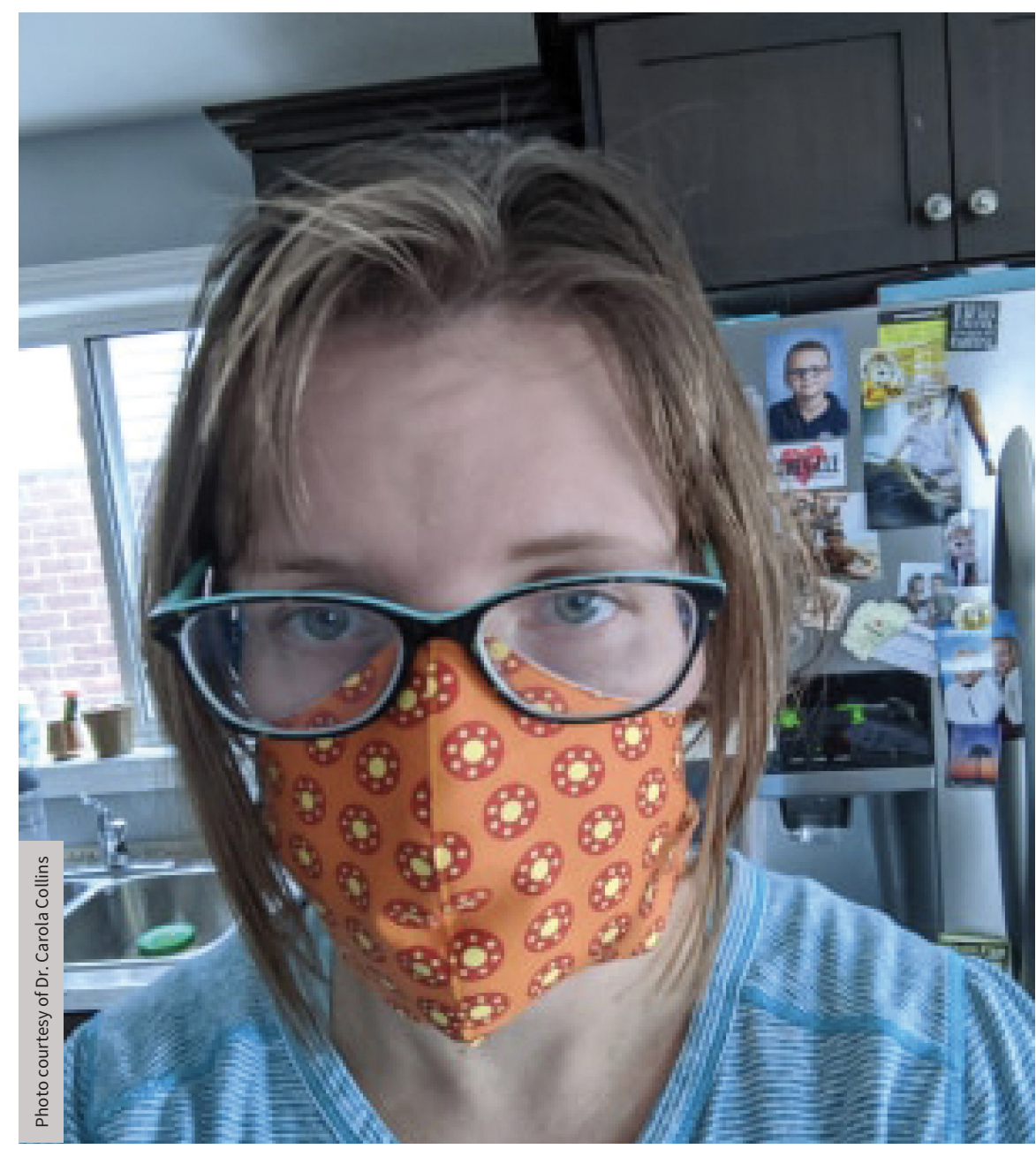

Without a supply of protective equipment, Ontario family physician Dr. Carola Collins and others have started making their own.

medicine at the University of Ottawa. "We definitely all received boxes with gowns, masks (over the ears, not N95), gloves, hand sanitizer and such," said Freedhoff. He's urging federal and provincial public health authorities to do the same now.

The lack of protective equipment is particularly challenging for clinicians who care for patients in vulnerable circum- stances. Personal protective equipment is running low among teams working with people experiencing homelessness, says Dr. Jeffrey Turnbull, medical director of Ottawa Inner City Health.

"We plan to open an isolation unit tomorrow and we will very quickly exhaust all personal protective equipment," Turnbull said. "If you don't have it, 
then you are putting your staff at an exceptional risk."

Turnbull, a past-president of the Canadian Medical Association, urged the provinces and public health officials to quickly distribute equipment.

Protecting people experiencing homelessness across Canada protects the health care system, he said. "We are doing our very best to protect the hospitals and the scarce resources we have there."

The federal government has acknowledged shortages, not just of personal protective equipment, but also ventilators and swabs for testing kits. Deputy Prime Minister Chrystia Freeland suggested in a March 19 news conference that money is not the problem. Equipment is in short supply globally.

"We are looking at every single option... whether it is the possibility of making some of this stuff [in Canada], whether it is various really extraordinary procurement efforts around the world that we are engaged in, and also knowing what everybody has so we can manage surges around the country," said Freeland.

Even though the federal government is leading the response to COVID-19, provinces and regions have been trying to smooth supply of protective equipment. "We've been trying to work at our regional tables to look at those local needs and see how they can be dealt with," said Dr. David Williams, Ontario's Chief Medical Officer of Health. For now, Williams is directing family doctors to send patients who may have COVID-19 to special assessment centres, rather than screen them unsafely in their practices, and encouraging more virtual care.

Laura Eggertson, Wolfville, N.S. 